\title{
Dynamic Method for Liaison of Community Pharmacists with National Programme for Tuberculosis Control: Efforts to Harness Untapped Opportunities
}

\author{
Rajeswari Ramasamy ${ }^{1 *}$, Guru Prasad Mohanta ${ }^{2}$, Shobha Rani R Hiremath ${ }^{3}$, Chandramouli \\ Ramnarayanan ${ }^{4}$, Raman Dang ${ }^{5}$, Manjiri S Gharat ${ }^{6}$ \\ ${ }^{1}$ Professor, Department of Pharmacy Practice, Krupanidhi College of Pharmacy, Bangalore, Karnataka, INDIA. \\ Current affiliation: Professor and Vice Principal, MVM College of Pharmacy, Bengaluru, Karnataka, INDIA. \\ 2Professor and Head, Department of Pharmacy, Annamalai University, Chidambaram, Tamil Nadu, INDIA. \\ ${ }^{3}$ Principal and Professor, Al-Ameen College of Pharmacy, Bengaluru,INDIA. \\ ${ }^{4}$ Professor and HOD, Department of Quality Assurance, Krupanidhi College of Pharmacy, Bengaluru, Karnataka, INDIA. \\ ${ }^{5}$ Principal and Professor, KLE College of Pharmacy, Bengaluru, Karnataka, INDIA. \\ ${ }^{6}$ Vice President, Indian Pharmaceutical Association-Community Pharmacy Division, Mumbai, Maharashtra, INDIA.
}

\begin{abstract}
Context: Revised National Tuberculosis Control Program (RNTCP) - Directly Observed Treatment-Short course (DOTS) strategy to involve Community Pharmacist (CPs), was conceived and implemented in India, with the objective of improving accessibility of Tuberculosis free medicines. Though the RNTCP personnel in the study area had tried to create liaison with CPs; and to train them in DOTS provision roles, it was not successful as CPs were not forthcoming to be a part RNTCP - DOTS paradigm. Hence this study was ideated and executed to develop a liaison model between CP and RNTCP personnel, to support the delivery of DOTS treatment under RNTCP programme. This article discusses the liaison method followed by the researchers to integrate the CPs with RNTCP'S TB centres in Bangalore City. Aim: To establish liaison between community pharmacists and RNTCP personnel to strengthen Public Private Mix (PPM) Partnership for providing TB care role in Bengaluru City, India. Methodology: An educational interventional study involving CPs in Bengaluru City was conducted with the regulatory support from Drugs Control department, Karnataka.Awareness and Training was given on the basis of the RNTCP training module for Community Pharmacist. The change in the level of awareness on existence of PPM RNTCP strategy among community pharmacist; and the percentage of pharmacists showing interest for TB care role after the program was measured. Results and Discussion: Out of $125 \mathrm{CPs}$ representations, $93 \mathrm{CPs}$ enrolled them as Private DOTS providers immediately after programme. The change in the Level of Awareness on the existence of TB-DOTS provider role was found to be $100 \%$ in this study. This result clearly points to the fact that CPs needs to be sensitized. Conclusion: The policy level changes in the ease of enrolling CPS to be a DOTS provider under the aegis of drugs control department, needs to be revisited and rethought in RNTCP's national strategy for pharmacists.
\end{abstract}

Key words: Tuberculosis, DOTS, Community Pharmacist, Public Private Mix Partnership, RNTCP, Public Health, DOTS Provider, National Programme.

\section{INTRODUCTION}

\section{Background of the study}

The Revised National Tuberculosis Control Programme (RNTCP) is a nationwide Tuberculosis (TB) control initiative of the
Government of India. This programme offers free diagnosis and treatment for TB based on World Health Organization (WHO) recommended 'Directly Observed
Submission Date: 10-04-2020; Revision Date: 08-06-2020; Accepted Date: 29-06-2020

DOI: 10.5530/ijper.54.3.133 Correspondence:

Prof. Rajeswari Ramasamy, Professor \& Vice Principal, MVM College of Pharmacy, Vikas Layout Maruthinagar, Venkatala, Yelahanka,

Bengaluru, Karnataka 560064. Research Center: Department of Pharmacy Practice, Krupanidhi College of Pharmacy, Bengaluru-560035, Karnataka, INDIA.

Phone: +91-9686993545

E-mail: rajeswari.vidula@gmail. com

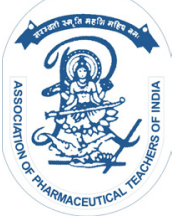

www.ijper.org 
'Treatment Short course' (DOTS) strategy. This strategy was introduced in 1997 in India, aftermath the declaration of TB as a global emergency by WHO. ${ }^{1}$ All TB suspects and $\mathrm{TB}$ patients are covered under this programme are entitled for free diagnosis and treatment in DOTS centers. DOTS strategy aims at assuring compulsory supervised treatment and accessibility of TB medicines to public. DOTS necessitate medicine administration to patient under direct supervision of the DOTS provider to ensure medication compliance. ${ }^{2}$ However, in this strategy, patient need to visit government health facilitybased DOTS center for each dose during the initial stage of DOTS implementation strategy in India. This causes inconvenience to patient who needs to commute to the DOTS center for each dose according to the working hours of DOTS center. This adds to the burden to the patients, who need to go about their wage earning and family supporting responsibilities, tending to skip the doses or discontinue the therapy. ${ }^{1-6}$ In addition, many young patients from urban areas have the stigma to visit health facility for DOTS therapy in comparison to the elderly population living in urban or rural areas. ${ }^{1}$

Health facility based DOTS for TB is impractical most of the time, as it more labour intensive owing to the busy schedules of physicians; and patients who need to travel and wait to fulfill DOTS therapy. ${ }^{6}$ Hence strategies involving community participation was designed and implemented in India, involving primary health care system, following the worldwide paradigms, to improve the accessibility to free $\mathrm{TB}$ diagnosis and medicines while reducing the social stigmatization.,

In most of the regions in India, even a lay person is trained to observe the DOTS therapy including grocery shop owners, NGO volunteers, private teaching hospitals and even female anganwadi workers. ${ }^{6}$ Many studies reveal that private sector retail medical outlets, also known as community pharmacies or chemists are often the first point of contact for any common ailments. In developed countries, community pharmacists are trained to deliver public healthcare roles including DOTS provision. This strategy might be possible for Indian community, due to community pharmacist's affordable services, convenience of access and lesser waiting time and lesser stigmatization associated with visiting a public or other private health facilities. ${ }^{8}$

Keeping this in view, Indian Pharmaceutical Association (IPA) - Community Pharmacy Division (CPD) mooted the concept of involving trained CPs as DOTS-TB providers in 2006. The International Pharmaceutical Federation (FIP) - World Health Organization (WHO) statement supported the DOTS-TB pharmacist role concept floated by IPA-CPD. A Memorandum of Understanding (MoU) was made in 2012, with Government of India, The Central TB division under Directorate General of Health Services and IPA- CPD, All India Organization of Chemists and Druggists (AIOCD) and Pharmacy Council of India (PCI) as stakeholders to involve the CPs in TB care roles. ${ }^{9}$ The central TB division has developed a Training module in collaboration with IPA-CPD for CPs in $2013 .{ }^{10}$ Further, IPA-CPD had taken initiatives to organize workshops to train CPs in few states, particularly in Central and North India, to foster collaboration with RNTCP centers to promote TB care. But this was not tried in Karnataka state by IPA-CPD yet. Though the RNTCP personnel in Bengaluru City have tried to create liaison with CPs to train them in DOTS provision roles, it was not successful as community pharmacists' responses were not forthcoming to be RNTCP centers, according to a conversation with RNTCP project coordinator of District Tuberculosis Office (DTO), Bangalore City(in 2016). This might have been due to the lack of official communication between RNTCP centers and CPs. This, prompted the researcher to initiate the effort to encourage, integrate and enroll the interested CPs in RNTCP as DOTS providers after the training. Though many workshops been conducted by IPA-CPD in other states, this was the first scientific formal study of sorts to be conducted in India to sensitize community pharmacists and to understand the changes in awareness level of CPs and their interests to participate in TB care role in Bengaluru city.

\section{AIM}

To establish liaison between community pharmacists and RNTCP personnel to strengthen Public Private Mix (PPM) Partnership for providing TB care role in Bengaluru City, India.

\section{MATERIALS AND METHODS Design and Study Settings}

This was an educational interventional study involving Community Pharmacists in Bangalore City, Karnataka state in India. (Figure 1). Ethical approval was obtained from the Institutional Ethical Committee in a tertiary care teaching hospital, in Bangalore. Education session was conducted by the investigators in teaching institution premises, located in the eastern part of Bangalore City. 


\section{Subjects}

Community pharmacy personnel whoever interested in attending awareness cum training programme for TB-DOTS pharmacist role in Bengaluru City were enrolled for the training programme. The respondents who completed the educational activity session were included in the study. The respondents who left in between the session were excluded from the study.

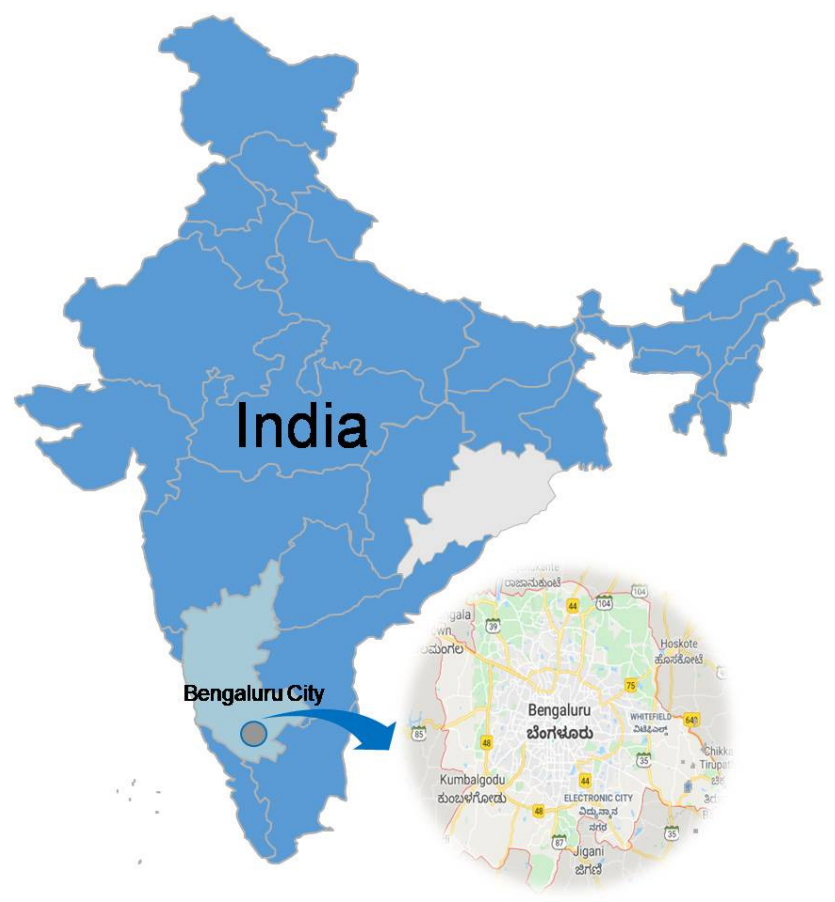

Figure 1: Geographical Location of the study Area.

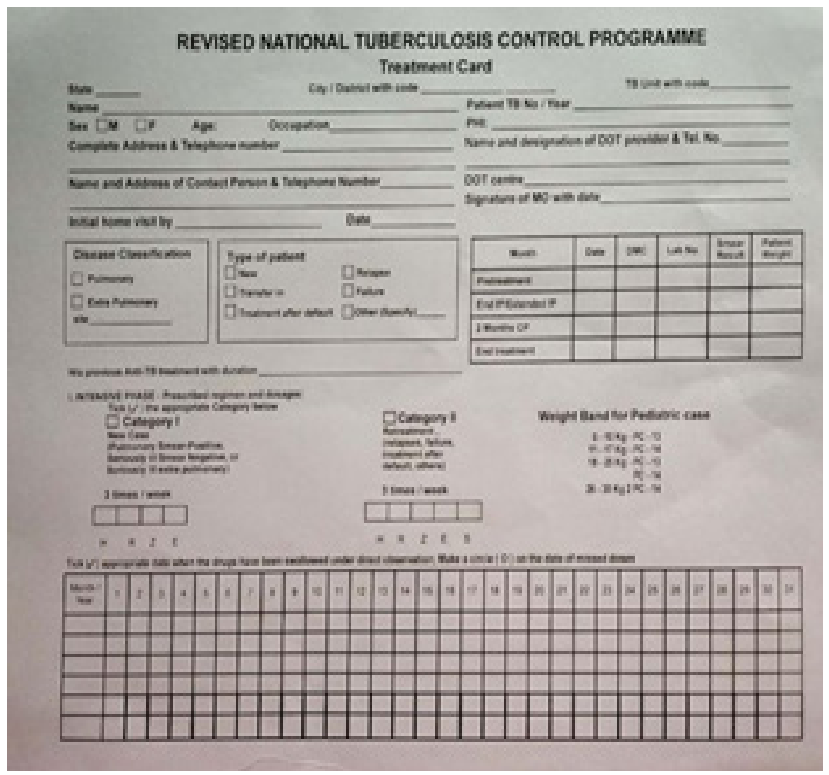

Figure 2.1: Model Patient Treatment Record Card (Front Page).

\section{Materials}

1. Copies of blank RNTCP's Patient treatment record card as in (Figure 2.1 and 2.2) for practice purpose; and RNTCP DOTS medicine 6 months course box for demonstration, preferably 1 set of medicine box for each 10 Pharmacists. Treatment cards and medicines obtained from Senior Treatment Supervisor (STS) at Tuberculosis Unit.

2. TB suspect referral forms to refer the suspected TB case to Senior Tuberculosis Laboratory Supervisor (STLS)

3. DOTS directory to each participant or Name and Phone number of STS and (Senior Tuberculosis Laboratory Supervisor) STLS area wise and list of Designated Microscopic Centers (DMCs) and DOTS centers from DTO.

4. Physical presence of STS and STLS at the training (so to connect them to pharmacists, area wise)

5. Advocacy, Communication and Social Mobilization (ASCM) material for use in Pharmacy (e.g. posters, leaflets) from State Tuberculosis Demonstration and Training Center (STDC) or through DTO.

6. Pharmacist's undertaking form as per the RNTCP Training module for Community Pharmacist, 2013.

7. Pre-test/Post-Test questionnaire to measure the change in awareness level, Knowledge, Attitude and Practicing interest of Community Pharmacists.

8. Participation certificate for the trained community pharmacists.

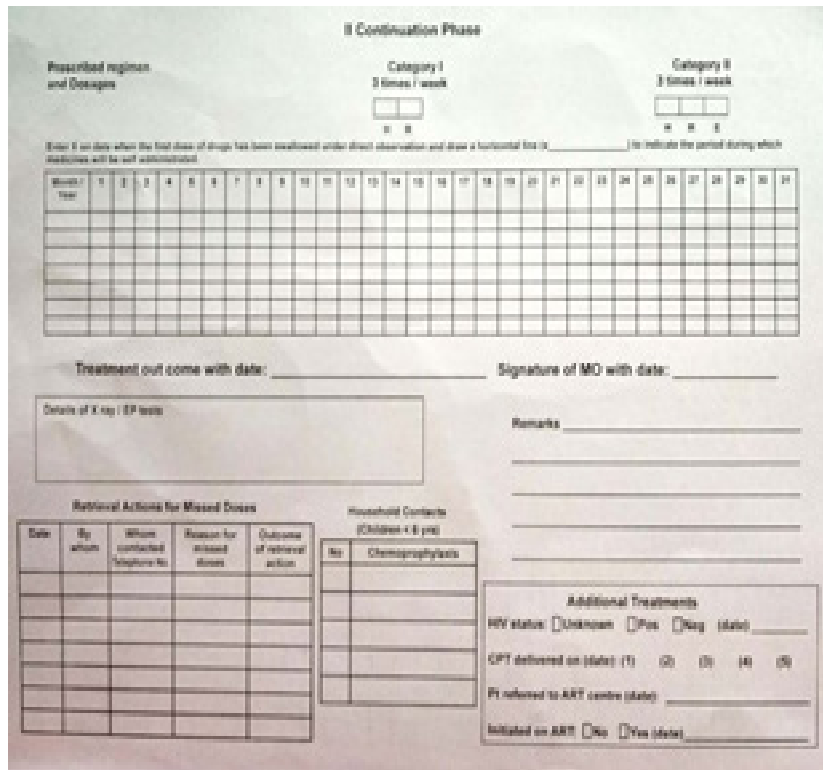

Figure 2.2: Model Patient Treatment Record Card (Back Page). 


\section{Procedure}

Primary investigator of researcher's team met the officials of RNTCP center, District Tuberculosis Office (DTO), Bengaluru City; and gathered the basic information on the status of community pharmacist's participation in DOTS provision and TB suspect referral role in their Jurisdiction. Researchers planned the modality of liaison methods to integrate and embed the community pharmacists with RNTCP team by involving Drugs Control Department of Karnataka, as a one of the stakeholders for this social cause as represented in (Figure 3). Researchers have approached Drugs Controller of Karnataka, request for an appeal to CPs to participate in public health initiative. An educational/ awareness programme was planned in collaboration with Drugs Control Department for CPs. An appeal from Drugs Control department was sent to the CPs of Bengaluru City, Circle 6 Jurisdiction, to register and participate in educational programme as envisaged in (Figure 4.1 and 4.2).Pharmacist's education/awareness was done on conducted on $20^{\text {th }}$ December 2016 by the investigator with the technical support from State TB Training and Demonstration Centre (STDC), Govt of Karnataka; and TB fact card-project lead, Indian Pharmaceutical Association- Community Pharmacy Division. Awareness and Training was given on the basis of the RNTCP training module for Community
Pharmacist, developed jointly by Indian Pharmaceutical Association (IPA) Community Pharmacy Division and Government of India, central TB division and in 2013. ${ }^{10}$ After the training programme, the interested chemists for the Public Private Mix (PPM) partnership to support the DOTS delivery were requested to give undertaking letter individually for participation in DOTS as per the format given in the annexure 2 of the Training module for Community Pharmacist, ${ }^{10}$ as represented in (Figure 5). The knowledge, attitude and Practicing interest of community pharmacist was tested using Pre and Post-test questionnaire. Interested Community pharmacists were provisionally enrolled for the TB suspect referral and DOTS provision role after the submission of 'undertaking form'. Necessary arrangements for issuing authorization letter (Figure 6) to store TB medications was done by sharing the medical shop details to DTO offices of Bengaluru City and Bengaluru urban districts. Pre-test and Post-test for pharmacist was conducted to assess their Knowledge, Attitude and Practicing interests. The certificate of attendance for the pharmacist was issued immediately after the feedback session. The model certificate issued is illustrated in Figure 7

\section{Data collection method}

Interested community pharmacists were asked to register their pharmacy and attending pharmacist name

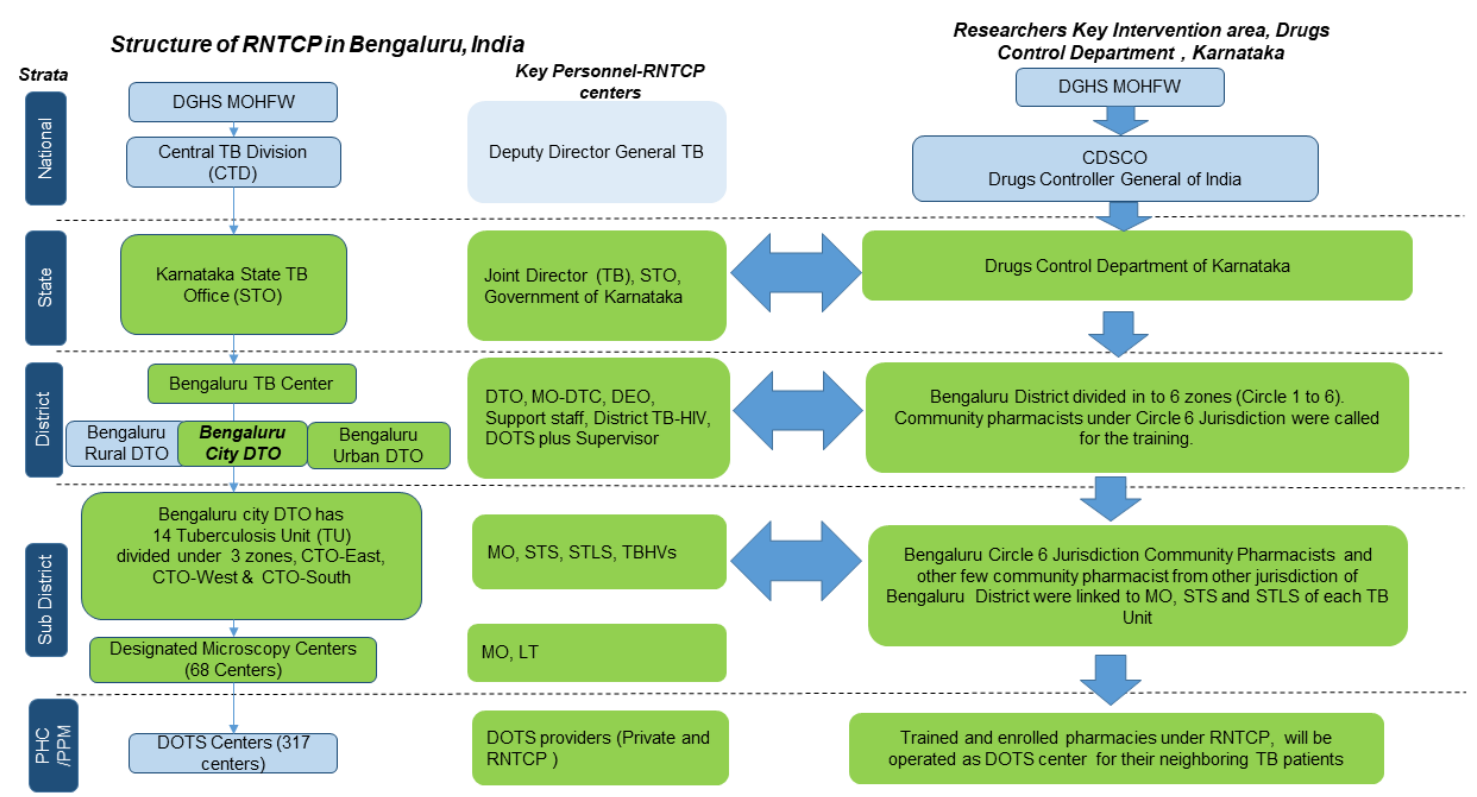

Figure 3: Key areas (marked in green) for establishing liaison to enroll private pharmacies under RNTCP. RNTCP-Revised National Tuberculosis Control Program, DGHS- MOHFW Directorate General of Health Services-Ministry of Health \& Family Welfare, CTD- Central Tuberculosis Division, STO - State Tuberculosis Office, DTO-District Tuberculosis Office, CTO-, PHC- Primary Health Center, PPM-Public Private Mix Partnership, DOTS- Directly Observed Treatment Short course, MO- Medical Officer, CTO- City Tuberculosis Office, STS- Senior Treatment supervisor, STLS- Senior Tuberculosis Laboratory Supervisor (STLS),CDSCO- Central Drugs Standard Control Organization, TBHVsTuberculosis Health Visitors, LT-Laboratory Technician 


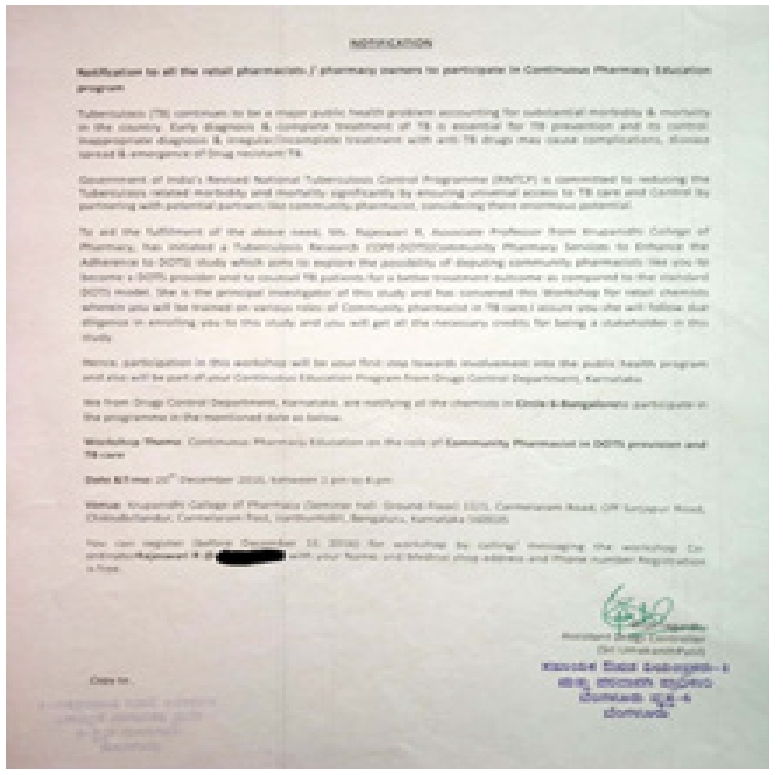

Figure 4.1: Model appeal Letter from Drugs control department to Community Pharmacist (English).

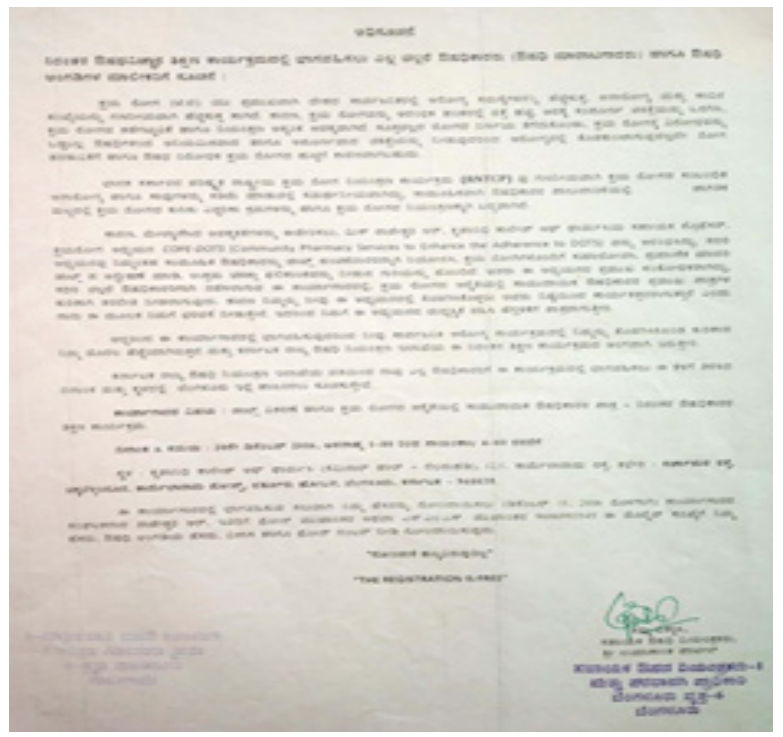

Figure 4.2: Model appeal Letter from Drugs control department to Community Pharmacist (Regional Language- Kannada).

with mobile number with the primary investigator. The basic demographics of pharmacist; and awareness level on the existence of government national strategy to involve private pharmacies as DOTS provider were done by using an online survey form using Google Forms. The URL of which was shared using WhatsApp to the participant before the advent of the programme.

\section{Outcome measures}

The change in the awareness level among community pharmacists on existence of national RNTCP strategy to involve community pharmacist; and the percentage

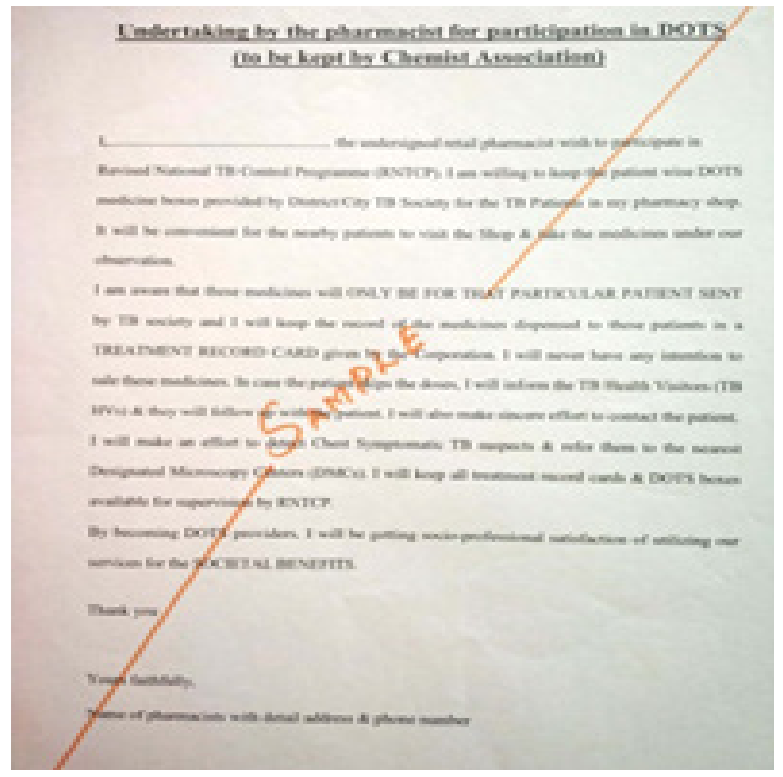

Figure 5: Model undertaking letter by the Community Pharmacist for participation in DOTS Strategy.

Sample format of Astheriazion Letter or NOC frow RNTCP o日 letterbead

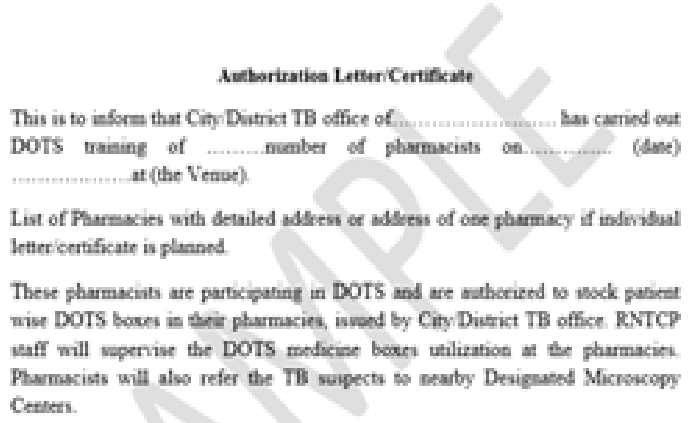

Sizn and Stamp of RNTCP officer

Figure 6: Sample format of authorization letter or Certificate from RNTCP.

of pharmacists showing interest for TB care role after the program.

\section{RESULTS AND DISCUSSION}

The 'DOTS' center should be a premises where Directly Observed Treatment (DOT) is given, convenient to both patient and DOTS provider. Community pharmacists are most accessible primary healthcare provider in India. Despite the inclusion of community pharmacist in Public-Private Partnership programme under RNTCP in India, for being a DOT provider, case finder and 


\section{CERTIFICATE OF TB-DOTS TRAINING}

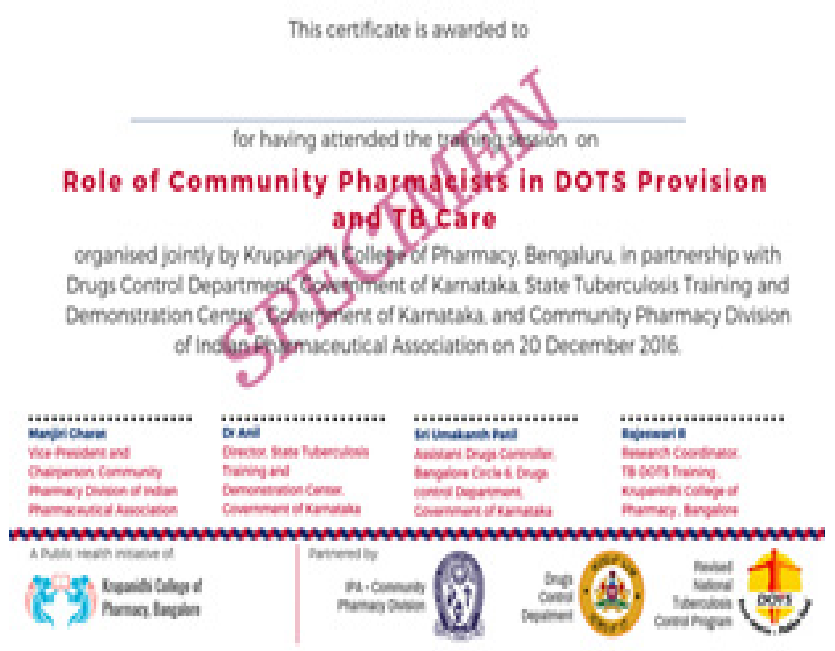

Figure 7: Specimen TB-DOTS Training Certificate. counselor in the training manual designed by central TB division, the awareness and training the pharmacist by central TB center is found inadequate in Karnataka due to lack of response from community pharmacists.

In this study, 149 CPs and /or owners, from Drugs Control office - Circle 6 Jurisdiction of Bengaluru city, attended the awareness cum training session. Majority of the participants were community pharmacists who are running their own medical store. The characteristics of the community pharmacists attended the programme is tabulated in Table 1.

Initially, the primary investigator approached community pharmacists, without involving Drugs control department as one of the stakeholders for the awareness cum training programme. Most of the pharmacists were unwilling to join the training, as they had concerns about their losing the business hours. Hence, the researcher used dynamic methodology to assemble the community pharmacist to this training session through Drugs Control department to enroll

\begin{tabular}{|c|c|c|c|}
\hline \multicolumn{7}{|c|}{ Table 1: Characteristics of the Community Pharmacies attended the } \\
Programme (N=125).
\end{tabular}

NA: Not Applicable

Table 2: Level of awareness, willingness and Enrollment status of sensitized community pharmacies for TBDOTS pharmacists' role ( $N=125)$.

\begin{tabular}{|c|c|c|c|c|}
\hline SN & Status of Community Pharmacist & Category & Freq & Percentage (\%) \\
\hline \multirow[t]{2}{*}{1} & \multirow{2}{*}{$\begin{array}{c}\text { Level of awareness on Existence of RNTCP } \\
\text { national policy to involve pharmacists in TB } \\
\text { care role }\end{array}$} & $\begin{array}{l}\text { Before receiving Notification from Drugs } \\
\text { Control department }\end{array}$ & 0 & 0 \\
\hline & & $\begin{array}{l}\text { After receiving Notification from Drugs } \\
\text { Control Department }\end{array}$ & 125 & 100 \\
\hline \multirow[t]{2}{*}{2} & \multirow{2}{*}{$\begin{array}{c}\text { Level of Awareness on role of TB-DOTS } \\
\text { Pharmacist role }\end{array}$} & Before the Programme & 0 & 0 \\
\hline & & After the programme & 125 & 100 \\
\hline \multirow[t]{2}{*}{3} & \multirow[t]{2}{*}{ Willingness for DOTS provision } & Willing & 123 & 98.4 \\
\hline & & Not willing & 2 & 1.6 \\
\hline \multirow[t]{3}{*}{4} & \multirow[t]{3}{*}{ PPM Enrollment Status } & $\begin{array}{l}\text { Given Undertaking to Join as DOTS } \\
\text { provider on the spot }\end{array}$ & 93 & 74.4 \\
\hline & & $\begin{array}{l}\text { Assured for giving undertaking after } \\
\text { discussing with Owner of medical Shop }\end{array}$ & 30 & 24 \\
\hline & & Not interested to enroll & 2 & 1.6 \\
\hline
\end{tabular}




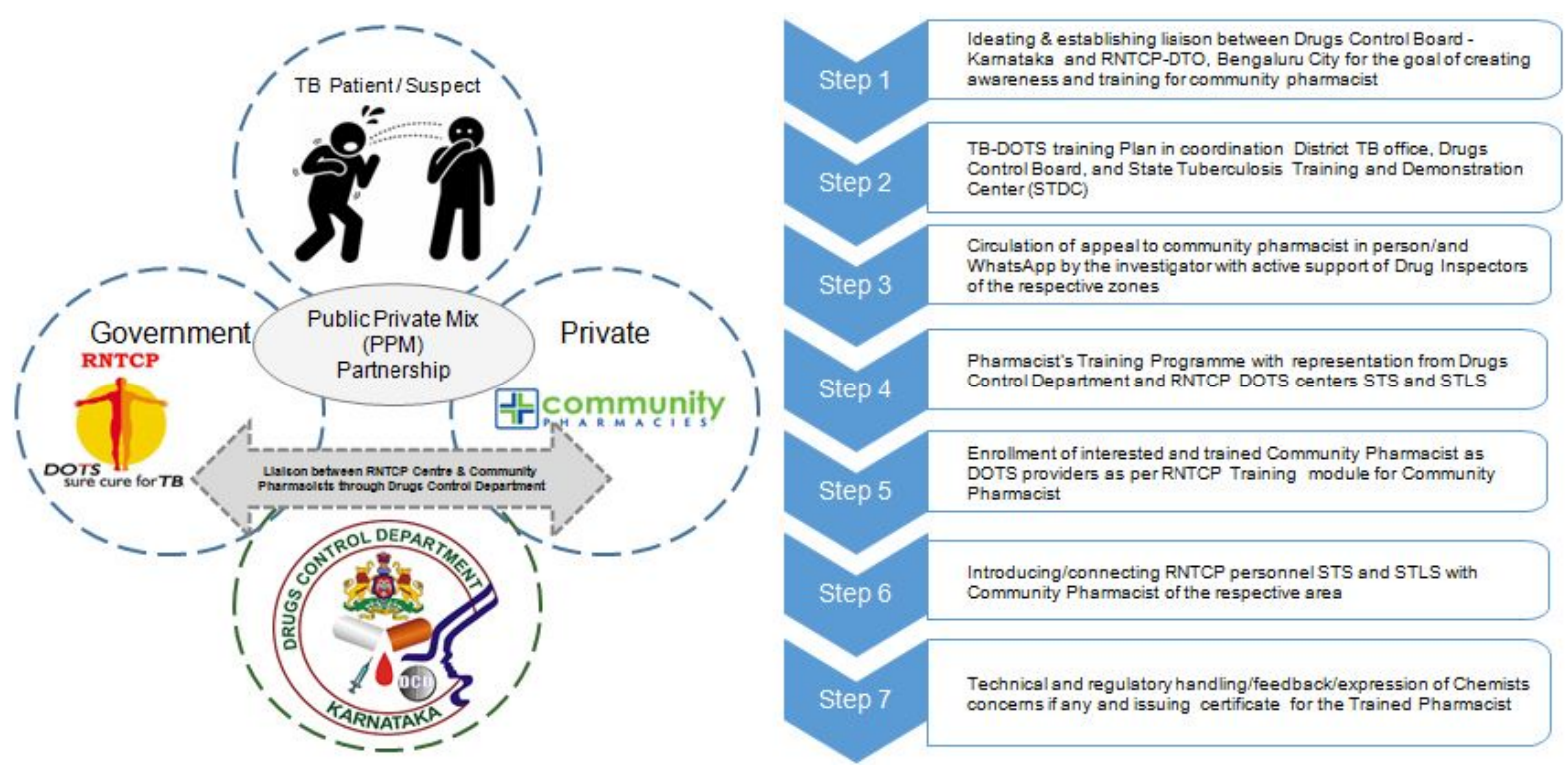

Figure 8: TB DOTS training - Liaison model devised for training the Community Pharmacists in Bengaluru City. RNTCP-Revised National Tuberculosis Control Program, TB-Tuberculosis, DTO-District Tuberculosis Office, DOTS- Directly Observed Treatment Short course, STS- Senior Treatment supervisor, STLS- Senior Tuberculosis Laboratory Supervisor (STLS), PPM- Public Private Mix, STDC-State Tuberculosis Demonstration and Training Center.

for the Educational / training programme as discussed in methodology section. The acceptance level for attending the programme was high, when researcher routed the appeal through the Drugs Control board, contrary to the situation described earlier. The main outcome of the programme was to establish the liaison between RNTCP TB unit and the practicing community pharmacist. As stated earlier this was perceived as a barrier by the personnel of DTO to enroll CPs as RNTCP stakeholders.

Out of 125 community pharmacy representation, 93 CPs enrolled them as DOTS providers immediately at the end of the programme (Table 2). The change in the Level of Awareness on the existence of TB-DOTS provider role for community pharmacists under RNTCP was found to be highly significant after the program. This result clearly points to the fact that CPs needs to be sensitized. The policy level changes in the ease of enrolling CPs to be a DOTS provider under the aegis of drugs control department, needs to be revisited and rethought in national strategy.

The modality discussed in this article may be replicated in various districts in all states to integrate community pharmacist in RNTCP services. Budding pharmacy interns from each pharmacy college can take up this initiative in their district, as part of their extended academic project. State Pharmacy Council and drugs control department in all states in India can extend their support to bring the community pharmacist in public healthcare role, than merely monitoring their commercial and regulatory aspects.

The common factors contributing to the hesitation and inhibition of the community pharmacist for enrolling as TB-DOTS pharmacist has to be studied in detail for the better understanding on the practical difficulties of chemists to deliver their role.

\section{CONCLUSION}

The potential of community pharmacists for healthcare provision under PPM partnership is untapped in India. This type of training is highly warranted to create awareness to community pharmacists and public on existing government policies in this regard to avail the benefits.

\section{ACKNOWLEDGEMENT}

Authors acknowledge the initiative of Mr. BT Khanapure, Drugs Controller of Karnataka, for his support, Mr Umakanth Patil, former Assistant Drug Controller, Bengaluru Circle 6 Jurisdiction, Bengaluru for facilitating this programme. Thanks are due to resource persons Dr. Anil, former Director, State Tuberculosis Training and Demonstration Centre, Govt of Karnataka; and Dr Arundhadhi Das, Project Coordinator, Society for Revised National TB Control Programme from Bruhat Bengaluru Mahanagara Palike (BBMP) for aiding the technical and liaison aspects of the training programme. 


\section{CONFLICT OF INTEREST}

The authors declare no conflict of interest.

\section{ABBREVIATIONS}

RNTCP: Revised National Tuberculosis Control Program; DGHS-MOHFW: Directorate General of Health Services-Ministry of Health and Family Welfare; CTD: Central Tuberculosis Division; STO: State Tuberculosis Office; STDC: State Tuberculosis Demonstration and Training Center; DTO: District Tuberculosis Office; CTO: City Tuberculosis Office; PHC: Primary Health Center; PPM: Public Private Mix Partnership; DOTS: Directly Observed Treatment Short course; MO: Medical Officer; STS: Senior Treatment Supervisor; STLS: Senior Tuberculosis Laboratory Supervisor (STLS); CDSCO: Central Drugs Standard Control Organization; TBHVs: Tuberculosis Health Visitors; LT: Laboratory Technician; TB: Tuberculosis; CPs: Community Pharmacists; WHO: World Health Organization; IPA-CPD: Indian Pharmaceutical Association - Community Pharmacy Division; FIP: The International Pharmaceutical Federation; MoU: Memorandum of Understanding; AIOCD: All India Organization of Chemists and Druggists; PCI: Pharmacy Council of India; BBMP: Bruhat Bengaluru Mahanagara Palike

\section{REFERENCES}

1. Vijayashree Y, Pierre L, Tullia B, Devadasan N, Patrick VS. Coping with tuberculosis and directly observed treatment: A qualitative study among patients from South India. BMC Health Services Research. 2016;16:283. DOI 10.1186/s12913-016-1545-9

2. Arora VG, Rajnish. DOTS strategy in India: The challenges. Current Medical Journal North Zone. 2002;8(4):19-27.

3. Lewis CP, Newell JN. Improving tuberculosis care in low income countries: A qualitative study of patients' understanding of "patient support" in Nepal. BMC Public Health. 2009;9:190. https://doi.org/10.1186/1471-2458-9-190

4. Marra CA, Marra F, Cox VC, Palepu A, Fitzgerald JM. Factors influencing quality of life in patients with active tuberculosis. Health Qual Life Outcomes. 2004;2:58.

5. Mohanarani S, Soumya S, Rajasekaran S, Beena ET, Arunkumar N, et al. Feasibility of Community DOT providers for Tuberculosis Treatment in HIV infected Individuals: A Pilot study. Indian J Tuberc. 2005;52(4):179-83.

6. Jaggarajamma K, Sudha G, Chandrasekaran V, Charles N, Thomas A, Santha $\mathrm{T}$, et al. Reasons for non-compliance among patients treated under Revised National Tuberculosis Control Programme (RNTCP), Tiruvallur District, South India. Indian J Tuberc. 2007;54(3):130-5.

7. Farmer P, Kim JY. Community based approaches to the control of multidrug resistant tuberculosis: introducing "DOTS-plus. BMJ. 1998;317(7159):671-4. doi: https://doi.org/10.1136/bmj.317.7159.671

8. Niranjan K, Emily D, Edmund R. Engagement of the private pharmaceutical sector for TB control: rhetoric or reality?. Journal of Pharmaceutical Policy and Practice. 2017;10(6):2-13. doi: 10.1186/s40545-016-0093-3

9. Memorandum of Understanding. The Central TB division Directorate General of Health Services. 2012. Retrieved on $14^{\text {th }}$ October 2015 from URL https:// www.fip.org/files/fip/news/MOU.pdf.

10. RNTCP Training module for Community Pharmacist. The Central TB division Directorate General of Health Services and Indian Pharmaceutical Association- Community Pharmacy division. 2013. Availablefrom https:// tbcindia.gov.in/showfile.php?lid=3154

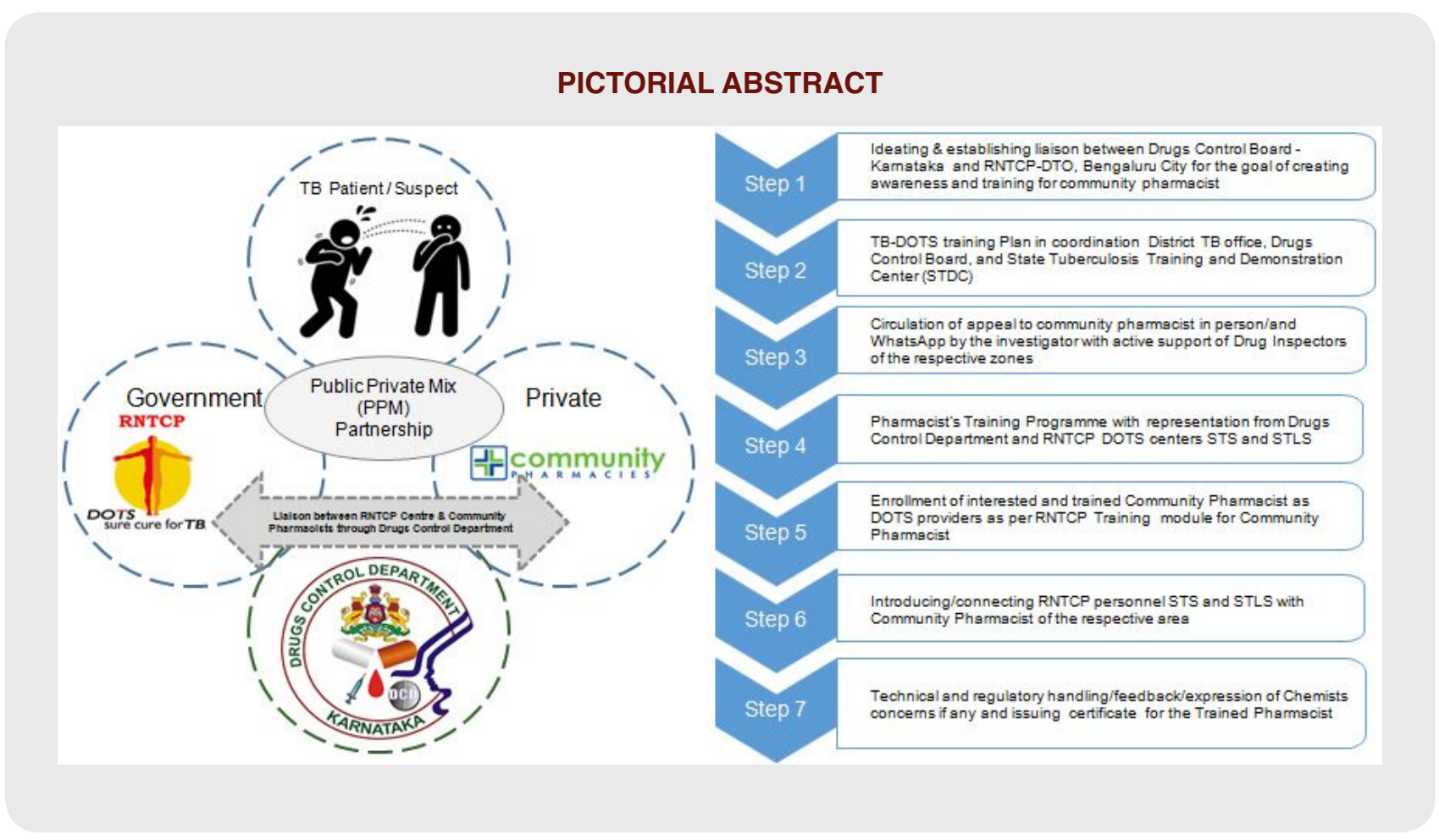




\section{SUMMARY}

This article explores the possibility of forging a Public-Private Mix (PPM) partnership Liaison model to link the Community Pharmacists with RNTCP-DOTS centers in Bangalore City. The authors propounded a dynamic methodology to assemble the community pharmacist to this training session through Drugs Control Department of Karnataka. The acceptance level for attending the programme was high, when researcher routed the appeal through official channels of the state's Drugs Control board. The training module prepared by Central TB division didn't identify Drugs Control Regulatory authorities as one of the main stakeholders. This was addressed in this study, which facilitated the process of linking RNTCPTB unit personnel and the practicing pharmacist. This study model can be replicated or modified based on the appropriate need by any research aspirant interested to bring the community pharmacist under the gambit of national programme for Tuberculosis; and also for the other public health roles during any national disasters. State Pharmacy Council and drugs control department in all states in India can extend their support to bring the community pharmacist in public healthcare role, than merely monitoring their commercial and regulatory aspects. The common factors contributing to the barriers of the community pharmacist for enrolling as TB-DOTS pharmacist can be studied in detail in future.

\section{About Authors}

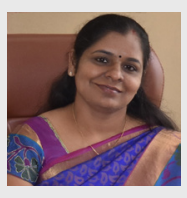

Rajeswari Ramasamy is a Professor in Pharmacy Practice and she has more than 17 years' of experience on Clinical pharmacy practice and extension methods. She also served in Pharmaceutical Industry for 5 years in developing Marketing Strategy, Product Management and Post Marketing Surveillance. Her research area includes Pharmaceutical Care, Pharmacovigilance and Public Health Research. She currently researches on newer paradigms on Tuberculosis care role of Community Pharmacists in India. She is serving as Incharge Principal at MVM College of Pharmacy, Bengaluru

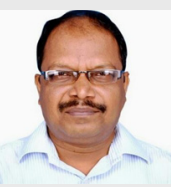

Guru Prasad Mohanta, is a world-renowned expert in the domains of Pharmacy practice, pharmaceutical policy, rational use of medicines and supply chain of medicines. He has authored several papers books and book chapters for both professionals and general public alike. He consults on pharmaceutical policy and rational use of drugs to international bodies like WHO and FIP. He has more than 30 years of teaching, research and administrative experience at various levels with over 500 articles to his credit. . He is the Professor and Head of Department of Pharmacy, Annamalai University, TN, India.

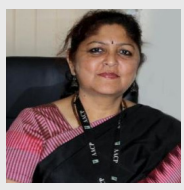

Shobha Rani R Hiremath is a Professor and Principal of Al-Ameen College of Pharmacy \& Dean-Pharmacy, Rajiv Gandhi University of Health Sciences. She is the recipient of Dr. Mumtaz Ahmed Khan Award for distinguished community service for the Exemplary and Yeoman Services rendered to the community through education in the year 2012. She has authored numerous papers, book chapters and supervised doctoral work in this domain. She is the Principal of Al-Ameen College of Pharmacy, Bangalore.

Chandramouli Ramnarayanan is the professor and Head of Department of Quality Assurance, Krupanidhi College of Pharmacy, Bangalore. He has worked in leading pharmaceutical manufacturing and Contract research organizations in quality assurance and regulatory compliance roles. He specializes in the domain of Pharmaceutical Quality by Design, numerical optimization and simulation of pharmaceutical processes. He is also a consultant statistician and hold the SAS certified Advanced Programmer credential. He follows regulatory and technological trends closely and is an advocate for open source technologies and computing. 


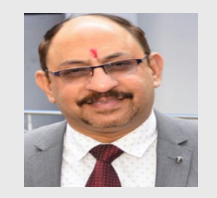

Raman Dang is a well known academic administrator of Pharmacy domain in India, and representing the interests of pharmacy profession in various forums across the world. $\mathrm{He}$ was the former registrar of DIPSARU, New Delhi. He is serving as Principal, KLE College of Pharmacy. He is also Secretary of Association of Pharmaceutical Teachers of India (APTI), to protect the interests of Pharmacy Teachers. His main area of project interests is developing Techniques to impart Quality Education \&Training of Trainers in Pharmaceutical and Health domains.

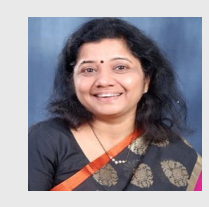

Manjiri Sandeep Gharat is a renowned Community Pharmacy and Consumer Medicine educator and Trainer from India. She is currently serving as Vice President and Chairperson of Community Pharmacy Division of Indian Pharmaceutical Association. She is very active in Community Pharmacy Section of the International Pharmaceutical Federation (FIP). She was instrumental in establishing public-private partnership engaging community pharmacists in TB DOTS programme in India. Gharat is also involved in professional development of pharmacists through Good Pharmacy Practices (GPP), to help them play a vital role in public health and to promote responsible use of medicines by pharmacists and patients.

Cite this article: Rajeswari R, Mohanta GP, Hiremath SRR, Ramanarayanan C, Dang R, Gharat MS. Dynamic Method for Liaison of Community Pharmacists with National Programme for Tuberculosis Control: Efforts to Harness Untapped Opportunities. Indian J of Pharmaceutical Education and Research. 2020;54(3):809-18. 